\title{
CONFLITOS SOCIOAMBIENTAIS EM ÁREAS PROTEGIDAS: DISPUTAS TERRITORIAIS NAS RESERVAS DE DESENVOLVIMENTO SUSTENTÁVEL MAMIRAUÁ E AMANÃ - AM
}

\author{
Social and environmental conflicts in protected areas: territorial contention in the Mamirauá and \\ Amanã sustainable development reserves - AM
}

\author{
Vinícius Galvão Zanatto \\ Mestre em Geografia. Instituto de Desenvolvimento \\ Sustentável Mamirauá, Tefé, Amazonas, Brasil \\ vinicius.zanatto@mamiraua.org.br \\ (Dhttps://orcid.org/0000-0002-1825-0097
}

Patrícia Carvalho Rosa

Doutora em Antropologia. Instituto de Desenvolvimento

Sustentável Mamirauá, Tefé, Amazonas, Brasil

patricia.rosa@mamiraua.org.br

OChttps://orcid.org/0000-0001-7570-3702

A lista completa com informações dos autores está no final do artigo

\begin{abstract}
RESUMO
As unidades de conservação se apresentam como a principal ferramenta de políticas públicas para conservação da sociobiodiversidade e a implementação destas exige a adoção de posturas relativas às regras e legislações ambientais para uso dos territórios e recursos, expresso no SNUC, gerando entre eles diferentes situações de conflitos socioambientais. Este texto busca compreender as lógicas de apropriações do território e dos recursos na Reserva de Desenvolvimento Sustentável Amanã (RDSA) e na Reserva de Desenvolvimento Sustentável Mamirauá (RDSM). Nesse contexto, especificamente abordamos as dinâmicas dos conflitos associados às situações de disputas entre moradores e usuários pelo controle ao acesso e uso de recursos, com o objetivo de conhecer e analisar as configurações sociais e políticas em que entre esses atores se estabelecem as interações para a formulação e execução de políticas de gestão ambiental e territorial, no âmbito das quais nos interessa aquelas relacionadas aos projetos de manejo participativo e compartilhado de recursos pesqueiros. Para isso, a perspectiva metodológica da ecologia política provê, a partir de suas análises, possibilidades de apreender tais conflitos e as relações estabelecidas entre os diversos atores sociais e institucionais, cuja dinâmica do conflito se dá a partir dos diferentes entendimentos do que é conservação e uma dificuldade de estabelecer as áreas de preservação e de uso para pesca em territórios sobrepostos. A percepção heterogênea dos recursos naturais, dos direitos territoriais e a apropriação do território são o plano de fundo dos conflitos nas áreas protegidas da região.
\end{abstract}

PALAVRAS-CHAVE: Recursos Naturais. Unidades de Conservação. Conflitos Territoriais. Amazônia

\begin{abstract}
Protected Areas are the main tool of public policies for the conservation of socio-biodiversity, their implementation requires the adoption of attitudes regarding the environmental rules and legislations for territories and resources use, expressed in SNUC, generating conflict situations. This paper seeks to understand the land and resource appropriation logic in the Amanã Sustainable Development Reserve (RDSA) and the Mamirauá Sustainable Development Reserve (RDSM). In this context, we specifically address the conflicts dynamics associated with situations of contentions between residents and users for control of access and use of resources, with the objective of knowing and analyzing the social and political configurations in which these stakeholders interact with each other for the formulation and implementation of environmental and territorial management policies, we are interested in those related to participatory and shared management of fishery
\end{abstract}


resources projects. For this, the methodological perspective of political ecology provides, from its analysis, possibilities to apprehend such conflicts and the relationships established between the various social and institutional actors, whose conflict dynamics are based on different understandings of conservation and a difficulty in establishing preservation zones and fishing areas in overlapping territories The heterogeneous perception of natural resources, territorial rights and land tenure are the background of conflicts in the protected areas of the region.

KEYWORDS: Natural Resources. Conservation Units. Territorial Conflicts. Amazon.

\section{INTRODUÇÃO}

No Médio rio Solimões e Afluentes o desafio à gestão compartilhada e integrada de Áreas Protegidas reside nas dinâmicas dos moradores e usuários no interior das Unidades de Conservação (UCs). A pesquisa aqui apresentada é conduzida em duas UCs de uso direto, as Reservas de Desenvolvimento Sustentável (RDS) Mamirauá e Amanã, criadas em 1996 e 1998, respectivamente, ambas sob gestão do estado do Amazonas e estabelecidas posterior e concomitante aos processos jurídicos federais de demarcação das Terras Indígenas nos seus entornos ${ }^{1}$. À altura de suas criações não se registrava entre os grupos indígenas e ribeirinhos, moradores e usuários históricos dessas áreas, registros de conflitos associados às disputas por territórios ou controle ao acesso e uso de recursos naturais (LIMA 2004, REIS 2005).

Diferentemente, essas populações locais alinharam-se em resposta as relações de poder vinculadas aos projetos políticos de colonização da Amazônia, cuja lógica de ocupação esteve continuamente forjada sob assentamentos de apropriação agromercantil, extrativista e de pesca, resultando na desigual distribuição de parcelas territoriais (FAULHABER 1997, 2011). A partir da década de 1970, em choque com seus interesses, indígenas e ribeirinhos acometidos pela escassez de pescado reúnem-se aos movimentos para contestação do caráter autoritário dessas relações assimétricas e hierárquicas que resultam em conflitos fundiários e, consequentemente, em processos de desterritorializações (ALENCAR 2006; PERALTA et al. 2015). Nesse período deu-se início a estratégia da "Preservação de Lagos", na qual pescadores urbanos, ribeirinhos e indígenas mobilizaram-se conjuntamente em projetos de conservação, apoiados pelas alas progressistas da igreja católica. Como efeito principal dessas ações gerou-se o apelo social, ambiental e científico à criação dos Territórios Protegidos na região (QUEIROZ, 2004).

1 TI Jaquiri, TI Porto Praia, TI Acapuri de Cima, à margem esquerda do rio Solimões; TI Marajaí e TI Tupã Supé, à margem direita do Solimões. TI Cuiu-Cuiu na margem esquerda do rio Japurá. 
Esses mesmos atores locais, a partir da década de 1990, tornaram-se, então, moradores das Terras Indígenas ou moradores e usuários das Unidades de Conservação (PERALTA, 2012).

Nesse percurso, com os direitos coletivos garantidos na Constituição, Souza (2011) e Santos (2012) mostram que a emergência dos conflitos existentes entre moradores e usuários no interior das UCs caracterizam nos anos 1990-2000 orbitando no entorno de questões políticas pelo reconhecimento e visibilidade de identidades étnicas. Com o advento do Decreto 169 da Organização Internacional do Trabalho e o reconhecimento da auto-identificação esses conflitos deslocam-se da questão identitária para processos de reconhecimento territorial diferenciado, materializado em situações de disputas controle, acesso e uso exclusivo das áreas de manejo pesqueiro entre indígenas e ribeirinhos

O que se passa na região parece seguir o complexo de um contexto global de aumento das áreas protegidas e dos sistemas de governança embasados na implementação de ferramentas de ordenamento territorial com a esperada adoção por parte das populações locais de posturas relativas às regras e legislações ambientais para uso dos territórios e recursos, obliterando escalas de interação, temporalidades e sentidos de apropriação dos territórios e do uso da terra. Sendo a criação de áreas protegidas uma das principais estratégias para mitigar os efeitos da perda de biodiversidade, com essas novas situações de disputas é imperativo pensarmos que os conflitos socioambientais tendem a dilatarem-se, especialmente pela fragilidade dos instrumentos de gestão associados à proteção e fiscalização, tornando sua efetividade uma problemática que envolve as instituições e a sua integração na gestão dessas áreas (CASTRO e NIELSEN, 2001, GELDMANN et al., 2015, RECHCIŃSKI et al, 2019).

Nesse sentido, o objetivo da pesquisa em desenvolvimento é compreender as diferentes lógicas de apropriações do território por grupo em interação, observando nas dinâmicas de conflitos entre eles como esses componentes relacionais e legais emergem. Desse modo, olhar para as dinâmicas locais gera condições para analisar as situações de conflitos socioambientais nas RDS Amanã e Mamirauá, permitindo observar e compreender os efeitos particulares dessas relações entre comunidades indígenas, ribeirinhas e as instituições na gestão compartilhada de recursos naturais nas Unidades de Conservação. 


\section{PROCEDIMENTOS METODOLÓGICOS}

A Ecologia Política tem seu foco nas relações das sociedades humanas com os ambientes biofísicos e as relações estruturais de poder entre as sociedades (LITTLE, 2006), evidenciando a existência de um número crescente de conflitos socioambientais por recursos naturais em que diversos grupos demandam seus direitos sociais, culturais econômicos e ambientais (ESCOBAR, 2005, 2006). Nessa perspectiva, a Ecologia Política oferece caminhos possíveis de se analisar as interelações existentes entre os grupos sociais, instituições e os ambientes biofísicos a partir da etnografia dos conflitos, buscando responder questões de quantidade, motivos, temporalidade e práticas de uso dos recursos naturais, bem como os impactos causados pelos conflitos na gestão e na efetividade da conservação da biodiversidade (STENGER, 2005; LITTLE,2006).

Nessa esteira, os conflitos socioambientais assumem diferentes dimensões, podendo estar relacionados com agricultura, pesca, caça ou com objetivos de conservação discrepantes entre as populações e os entendimentos legais sobre territórios, gerando os conhecidos casos de exclusão de pessoas de áreas protegidas e colisões ontológicas (REDPATH et al., 2013; MENDES, 2006; CARDOSO ET AL, 2020). No Brasil, as áreas protegidas como instrumento de governança ambiental e territorial enfrentam diversos desafios, alguns ligados aos processos de mudanças climáticas, outros a mudanças nas formas de hospedar o tema nas políticas ambientais, e restam aqueles inerentes ao processo de criação, zoneamentos e definições de limites e regras, por exemplos (BENSUSAN \& PRATES 2014). Sendo assim, os conflitos socioambientais resultam do modo diferenciado em que forças opostas se relacionam e interpretam as possibilidades de acesso uso, controle de recursos e ambientes (LITTLE, 2001, REDPATH et al., 2013). Nesse sentido, conhecimentos, experiências, ideologias de cada ator afetam a dinâmica das relações estabelecidas nos conflitos (ADAMS et al., 2003).

Os conflitos socioambientais transitam, portanto, em diversas escalas espaciais e organizacionais em um sistema socioecológico entrelaçado e um mesmo ator pode atuar em escala local, regional, nacional ou global (LITTLE, 2006). De modo similar as escalas diferenciadas de socialidades constituinte do sistema social, o sistema ecológico também opera orientado pela multiplicidade de perspectivas, a exemplo do que ocorre com os sistemas de florestas tropicais presentes nas latitudes médias, passando para o nível do bioma Amazônico, que, por sua vez, pode ser separado em bacias hidrográficas, em 
fitofisionomias, e, no nível local, em sistemas de lagos, como o vemos nos ambientes de várzea onde situam-se as RDS, foco de estudo. Diante de uma malha de relações e escalas, temporais e espaciais, a etnografia de conflitos que nos interessa produzir busca conhecer os diferentes sistemas de governança que interagem entre si, articulando objetivos distintos que mobilizam as situações de disputas nos múltiplos territórios e perspectivas de apropriação sobrepostas nas RDSs. Nosso foco está voltado as interações e interelações dos diferentes grupos sociais envolvidos nas disputas, e, a partir desse ponto, identifica-se os variados interesses por recursos e territórios, bem como as cotas de poder estabelecidas; analisa-se os recursos naturais em disputa, os impactos gerados e as interações dos grupos com o meio biofísico (LITTLE, 2006).

Em síntese, a abordagem da Ecologia Política nos sugere a elaboração da relação de conhecimento como uma linguagem processual, no interior da qual as condições históricas, socioculturais e ambientais que relacionam os atores sejam consideradas. Esta perspectiva analítica nos possibilita gerar nessa pesquisa elementos para a compreensão das flutuações semânticas no emprego das noções conservação, sustentabilidade e de conflitos a ela associados. Se faz necessário para isso entender em que termos relacionais e políticos se dão as práticas pela conservação, ou não, em nível local; das interações dos atores indígenas e ribeirinhos, e suas estratégias e narrativas sobre eventos de conflitos na interação com as regulamentações estatais que os circunscrevem enquanto habitantes de áreas protegidas.

\subsection{Identificação de conflitos}

A pesquisa identifica os conflitos e as interações dos atores a partir de cinco dimensões fundamentais para se estabelecer um sistema de governança: Institucional, Econômica, Cognitiva, Social/ Cultural e Ecológica (Figura 1). As dimensões Social/Cultural e Cognitiva são pré-requisitos básicos para o estabelecimento dos conflitos e influenciarão as outras dimensões (RECHCIŃSKI et al, 2019). Destarte, ao olhar para os padrões das interações sabe-se que sua estruturada desloca-se dentro de organizações sociais formais ou por interações informais entre os atores, onde cada diferente percepção e experiências nessa malha influenciará as outras dimensões, dando a cada conflito uma dinâmica particular. 
Figura 1 - Estrutura de identificação de conflitos socioambientais.

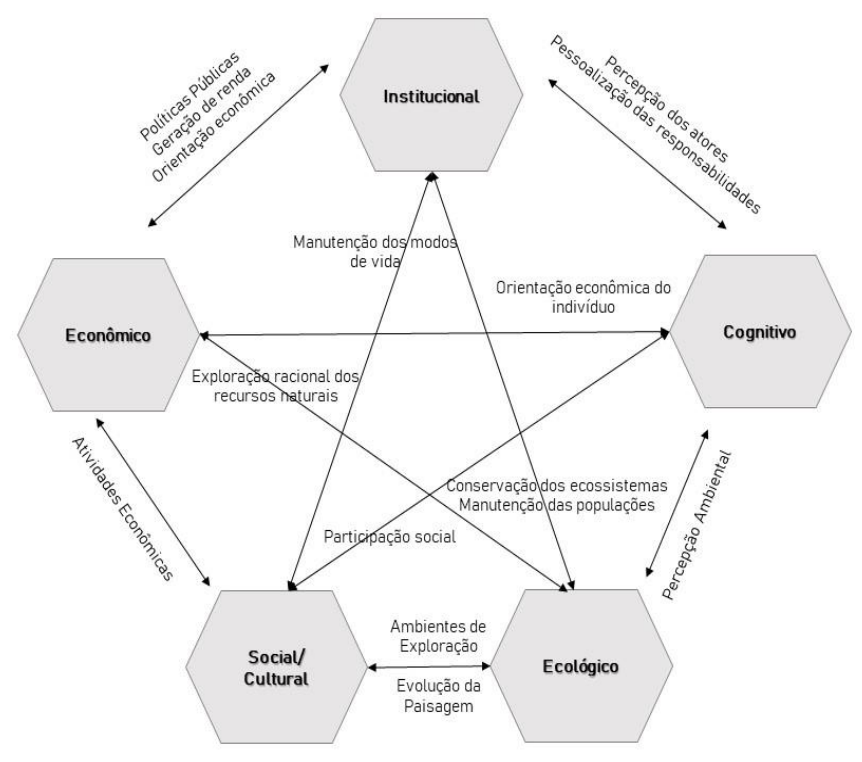

Fonte: Adaptado de Rechciński et al, 2019.

\subsection{Coleta e análise de dados}

A análise foi conduzida a partir de pesquisa bibliográfica e documental e complementada pelo trabalho de campo realizado no setor Boa União, situado na RDS Amanã, mas cujos territórios pesqueiros em disputa localizam-se sobre a RDS Mamirauá, na margem direita do rio Japurá. Nesse setor, a mais de uma década há registro de comunidades indígenas gerindo práticas de manejo de espaços de uso com comunidades ribeirinhas. Nesse contexto, a pesquisa bibliográfica ocorreu com intenção de fundamentar o teor dos conflitos e a formação socioespacial das comunidades e áreas protegidas inseridas no âmbito desse estudo. Essa etapa inicial de identificação dos atores e territórios que os interelacionam nas situações de conflitos foi executado embasada na análise de documentos de primeira mão e relatórios técnicos, tendo sido analisadas também atas das reuniões ocorridas com as comunidades moradoras e usuárias do setor Boa União no período de 2001 a 2016.

Com tal procedimento, buscou-se sistematizar o histórico de conflitos e acordos realizados pelas comunidades e instituições envolvidas na gestão das reservas, especialmente no quesito mais sensível da gestão, o zoneamento e ordenamentos dos ambientes pesqueiros entre eles, pivô dos desentendimentos relacionados as tais regras de acesso e uso de recursos e estratégias locais de compartilharem territórios. 
O trabalho de campo foi conduzido para compreender como os atores sociais interpretam os conflitos, se relacionam em projetos por conservação da sociobiodiversidade e constroem seus projetos territoriais no interior das RDS. Para tanto, a observação participante e o acompanhamento de reuniões comunitárias e fóruns deliberativos das RDS Amanã e Mamirauá resultou no mapeamento das posturas discrepantes e entendimentos plurais em relação à ideia de conflito bem como de conservação e sustentabilidade, quando os interlocutores afirmam que o "conflito não é por causa da Reserva e as suas regras", senão que os modos distintos e variados através dos quais "nós, os moradores e usuários, indígenas e ribeirinhos, entendemos como as regras da preservação funcionam nos territórios disputados". Os interlocutores, indígenas e ribeirinhos, parecem concordar em um ponto, contudo, reafirmando o anterior: "todos, indígenas e ribeirinhos, queremos terra e peixe, mas nem todos querem seguir regras, dai, vem os conflitos, os desentendimentos entre nós".

\section{3 ÁREA DE ESTUDO}

A pesquisa é conduzida no Médio Solimões, mais especificamente na calha do rio Japurá, em uma região formada por ecossistema de várzea. A várzea se caracteriza pela inundação periódica de ambientes florestais, arbustivos e de campos a partir da rede de drenagens causando mudanças físico-químicas no ambiente (JUNK et al., 1989; JUNK 2005; JUNK et al., 2012).

A área delimitada para estudo localiza-se nas Reservas de Desenvolvimento Sustentável Mamirauá, justaposta à Terra Indígena Cuiu-Cuiu, identificada em 1994, e cujos moradores são usuários das mesmas áreas que os indígenas e ribeirinhos da RDS Amanã, já tendo havido um histórico de engajamento desses nas ações compartilhadas de gestão de recursos pesqueiros e de proteção ambiental. As comunidades foco da pesquisa são: Jubará e Açaituba, localizadas na RDS Amanã, e interlocutores moradores nas aldeias São Pedro, Vila Nova II, Nova Esperança, Nova Estrela, Vila Nova e São José do CuiuCuiu, localizadas na Terra Indígena Cuiu-Cuiu (Figura 2). 


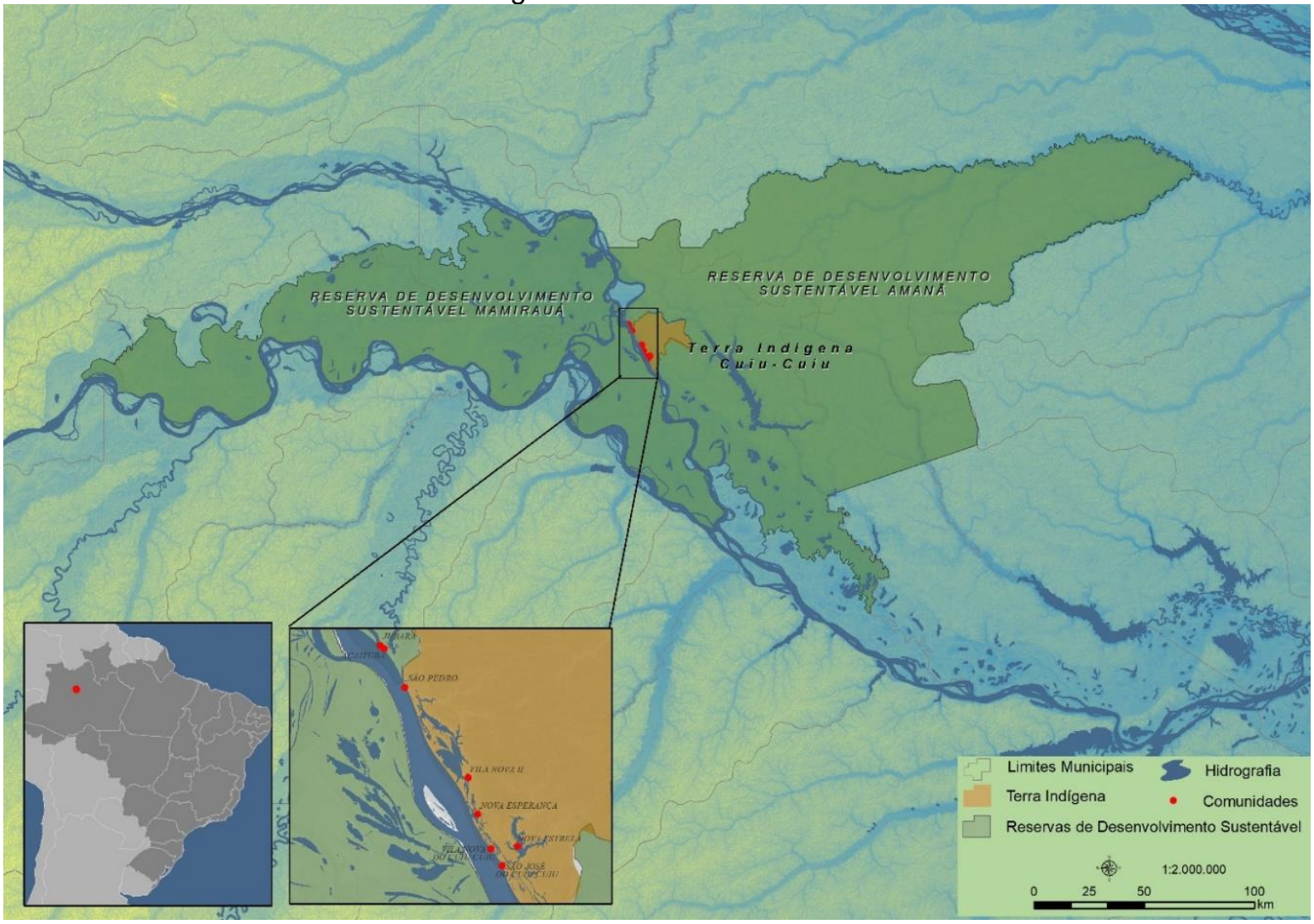

Fonte: IDSM/ Elaboração: Vinícius Galvão Zanatto

A RDS Mamirauá foi primeiramente estabelecida como estação ecológica em 1990, sendo no ano de 1996 foi recategorizada como Reserva de Desenvolvimento Sustentável, a primeira do tipo no Brasil. A RDS Mamirauá possuí 11.240 km² e abrange 5 municípios (Tonantins, Japurá, Maraã, Uarini e Fonte Boa). No levantamento sociodemográfico, atualizado em 2019, a reserva contava com 136 localidades e uma população de 6.151 pessoas.

A RDS Amanã foi estabelecida no ano de 1998, e possui uma área de 2.350 .000 ha e abrange 4 municípios (Maraã, Coari, Codajás e Barcelos). Existem 133 localidades e uma população de 5.458 pessoas (NASCIMENTO et al., 2019).

A Terra Indígena Cuiu-Cuiu teve seu processo de demarcação iniciado em 1992, sendo identificada e reconhecida em 1994, e sua homologação no ano de 2003, cuja área demarcada situa-se no município de Maraã e está justaposta a RDS Amanã, com uma extensão territorial de 36.310 ha e de ocupação da etnia Miranha, e uma população estimada em 721 habitantes em 6 aldeias, de acordo com os dados do Distrito Sanitário Especial Indígena (DSEI) que os assiste. 
Como apontado anteriormente a igreja católica teve um papel fundamental na mobilização da população do Médio Solimões para preservação dos lagos e fortalecimento comunitário. Tal importância se expressa nos níveis de organização política das comunidades e nas instâncias de diálogos estabelecidas entre os setores da UC, que são espaços territoriais definidos agrupando em seu âmbito comunidades da Reserva e de entorno que compartilham os recursos naturais do território (MOURA et al., 2016). As comunidades aqui estudadas são reconhecidas e legitimadas como moradoras e usuárias do setor Boa União, tendo cada uma delas sua representação local, e enquanto setor, dois representantes no Conselho Deliberativo da RDS Amanã, atualmente um da comunidade indígena Jubará, outro da comunidade ribeirinha Açaituba.

As comunidades estão localizadas na Terra Indígena Cuiu-Cuiu e na RDS Amanã, à margem esquerda do Rio Japurá, entretanto são usuárias dos lagos presentes na RDS Mamirauá, margem direita do mesmo rio. Dessa forma, atores sociais e institucionais se sobrepõem a partir de territorialidades distintas e o conflito emerge nos diferentes usos que se faz do território (Figura 3). 
Figura 3 - Divisão dos lagos por comunidade - Setor Boa União

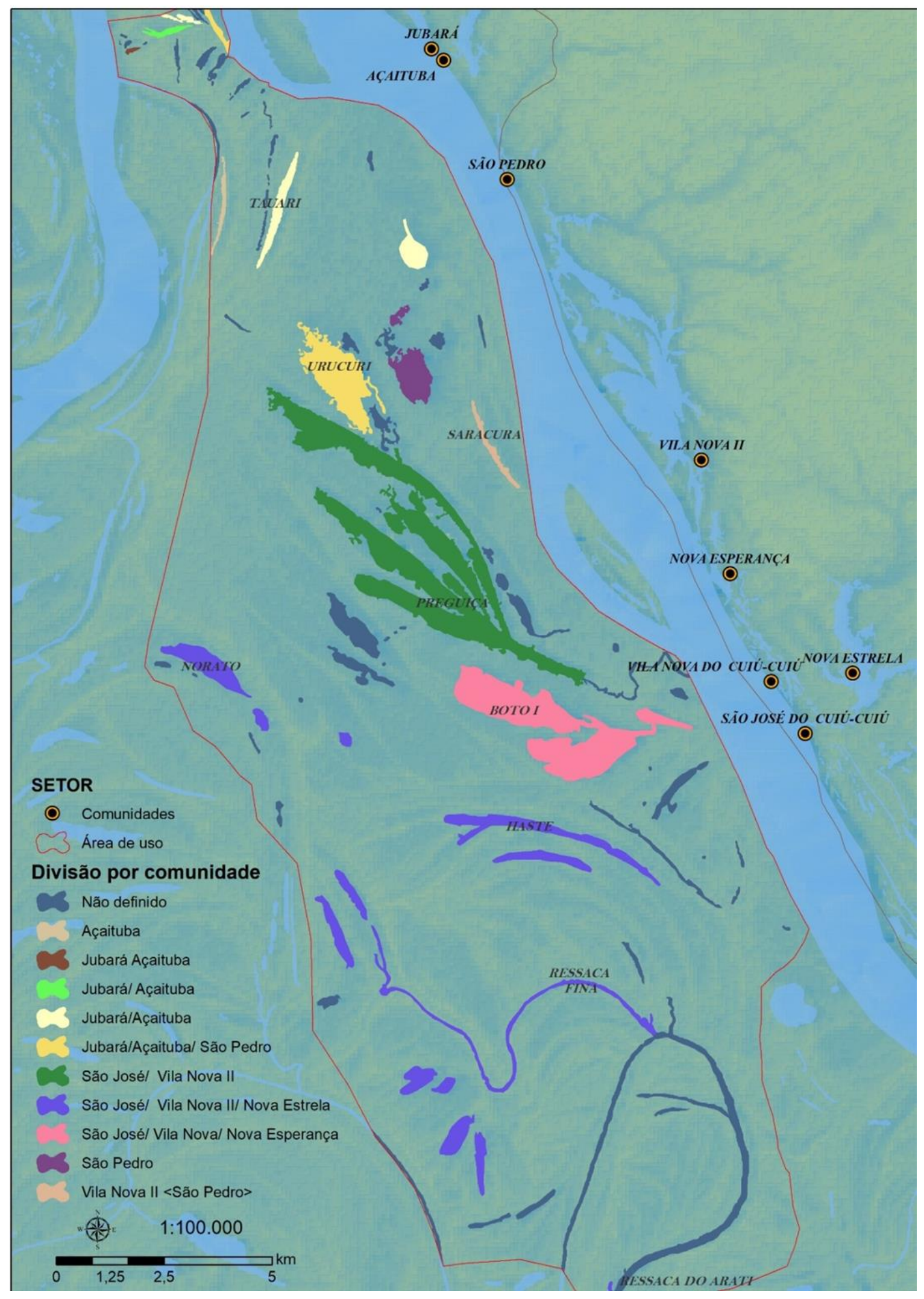

Fonte: IDSM/ Elaboração: Vinícius Galvão Zanatto 


\section{DISCUSSÃO E RESULTADOS}

Raffestin (1993) aponta que o território é resultado das ações humanas com objetivo determinado e revela as relações marcadas pelo poder. Nesse sentido, o Estado constrói sua territorialidade a partir das intencionalidades e conceitos jurídico-ambientais específicos, sendo as Áreas Protegidas, UCs ou Terra Indígenas, formas-Estadwo operando como ferramentas de ordenamentos territoriais diversos, os quase, na década de 1990, insurgem como fusão de instrumentos de governança visando compatibilizar os interesses e direitos territoriais, sociocultuarais e ambientais dos Povos Tradicionais (CARNEIRO DA CUNHA, 2009).

Os conflitos aqui estudados ocorrem nos territórios coletivos dos acordos de pesca. Esses territórios transitam entre duas esferas conectadas: a do território do Estado, decretado como RDS, que pressupõe a adoção de condutas territoriais e práticas econômicas sustentáveis, e a dos territórios locais, das comunidades de moradores e usuários dos lagos das Reservas. Nesses territórios de pesca, os conflitos orbitam em torno do controle e acesso aos recursos, fragilizando atividades de gestão, criando a necessidade uma arena de discussões para a proposição de mecanismos integrados de compatibilização entre os atores envolvidos.

As comunidades moradoras das RDSs historicamente dialogam entre elas para criarem e gerirem as lógicas de "repartir o território", seja como comunidades seja como setores políticos que as agrupam, e nessa interação definem as categorias e zoneamentos bem como as responsabilidades de cuidados, "zelar", dos lagos para uso e preservação de cada uma. De 2001 a 2016 foram catalogadas pelo menos 5 configurações diferentes na distribuição dos lagos e categoria de manejo no setor Boa União.

Uma constante nas declarações dos comunitários é a dinâmica das "invasões dos lagos". A categoria de invasores tanto como a situação que a acompanham, o conflito pelo acesso e direitos de uso, têm sentidos múltiplos (SOUSA, 2005). No setor Boa União, composto por duas comunidades, Jubará e Açaituba e as 6 aldeias da $\mathrm{Tl}$, os atos de invasão, caracterizados por pescar em lagos zoneados a outrem, não ocorrem por pessoas externas às áreas protegidas, e sim por eles mesmos. Essa conduta do invasor é apontada pelos interlocutores como motivo para a desmobilização dos participantes no acordo de pesca, posto que ao noticiar moradores ou usuários "mexendo no lago de outra comunidade", desencadeia-se uma reação de desconfiança e ao mesmo tempo de 
sentimento de prejuízo, acarretando tanto na fragilização da conservação quanto das práticas de gestão de bens comuns.

Nessa esteira, E. Ostrom $(1990,1998)$ argumenta que o "dilema da ação coletiva" permite entender as dinâmicas de interdependência citadas sob a ótica da dificuldade de estabelecer princípios na gestão. Nosso caso em estudo, destaca-se o problema da definição de fronteiras, sejam elas áreas de uso sejam elas os direitos e regras de propriedades entre os atores no território. Isso resulta na ruptura da lógica da reciprocidade, que uma vez interrompida, gera novas ondas de invasões. Afinal, se as normas correspondem aos valores internos do grupo, criadas e controladas pelo coletivo, quando não são por eles efetivas e "respeitadas", elas não constituem uma incitação à cooperação e ao compartilhamento. O setor Boa União possui boa parte de sua área em na zona de preservação permanente da reserva, portanto, os lagos inseridos não poderiam ser empregados para a pesca. Entretanto, o que ocorre na prática é que parte dos lagos são utilizados pelas comunidades para subsistência, tornando ambientes de manutenção familiar ou comunitária.

Diante desse contexto e suas contradições em 2008 foi negociado com as comunidades da Terra Indígena Cuiu-Cuiu (São José, Vila Nova e Nova Estrela) quais locais seriam os ambientes pesqueiros destinados para a preservação permanente e aqueles que continuariam a ser utilizados pelas comunidades para subsistência e comercialização de pescados. Essa inconstância no estabelecimento e execução dos acordos nos revela atores locais e formas de governabilidades orientadas por projetos territoriais distintos e compreensões singulares da paisagem frente a frente, especificamente quando a disputa extrapola os limites físicos do território e necessita ser analisada também a partir da ótica cognitiva, ou seja, da percepção e conhecimentos que os atores possuem dos recursos naturais e da sustentabilidade (ADAMS et al., 2003).

Alguns atores indígenas aqui envolvidos se compreendem como atores diferentes das comunidades ribeirinhas, não devendo seguir as mesmas regras que essas, a despeito de serem usuários de uma área que é regulamentada como unidade de conservação e não Terra Indígena. Nesse âmbito, suas formas de atuar e interagir nos territórios exige diálogo mínimo com os gestores do Estado, quem, por sua vez, compreendem o zoneamento da unidade de conservação de uma outra forma. Os indígenas não possuem em seus processos identitários ou culturais a prática do manejo pesqueiro como é proposto pelas instituições, e é nesse ponto em que os conflitos emergem e os acordos acabam por não funcionar, ou operam por pouco tempo. 
Tanto indígenas como ribeirinhos compreendem a conservação dos recursos como algo positivo, mas se for para utilizar como um recurso econômico. Para essas comunidades a conservação deve ser feita com intenção de desfrutar dos recursos posteriormente, ou seja, preserva-se o lago agora para que no futuro possam utilizá-lo como fonte de renda, enquanto cientistas e gestores ambientais pensam a conservação a partir de critérios ecológicos de manutenção dos ambientes sem seu uso econômico direto (PERALTA e LIMA, 2015). As pessoas que vivem nos territórios extrativistas sofrem maior pressão econômica para a retirada do recurso que aqueles que vivem nos centros urbanos e apenas pensam em sua conservação (NEWIG e FRITSCH, 2009).

É necessário apontar as barreiras existentes entre as formas de governança institucionais e as governabilidades locais, no sentido de que as comunidades, tanto indígenas como ribeirinhas, possuem dificuldades em navegar pelo sistema legal de posse e uso dos recursos naturais por não compreenderem ou se apropriarem dos processos de modo uniforme, e, como ocorre no setor Boa União, não possuírem a assessoria necessária para a gestão de seus interesses (CASTRO e NIELSEN, 2001). O Estado por meio das instituições e gestores exerce seu poder enquanto ator com maior força para impor suas demandas, que flutuam de acordo com políticas de governo e interesses econômicos. Mediante tal conjuntura, como tornar os acordos de pesca instrumentos eficazes na gestão dos territórios, recursos e dos conflitos nas RDSs?

Visto isso, a gestão institucional integrada e localmente compartilhada com a participação dos usuários e moradores nas tomadas de decisão em todos os níveis de governança é estratégica para pensar a conservação dos recursos naturais em longo prazo. $\mathrm{Na}$ mesma medida que novas formas de participação e o reconhecimento das governabilidades sejam mais ativas e com poder de decisão para que os interesses econômicos e de subsistência das comunidades sejam respeitados e efetivados, ocorrendo de modo sustentável, preservando os recursos naturais paras as gerações futuras e garantindo a qualidade de vida desses sujeitos no presente.

\section{CONSIDERAÇÕES FINAIS}

Os múltiplos territórios que compõem o setor Boa União estão sobrepostos e diante da diversidade de territorialidades cada ator interpreta o recurso natural, o conflito e sua possível resolução de forma singular (ADAMS et al., 2003; LITTLE 2001). Portanto, é necessário que a leitura e mediação dos conflitos sejam realizadas de forma participativa, 
concebendo que nem todos os atores ficarão satisfeitos com as mudanças exigidas por uma gestão compartilhada, podendo assim intensificar os conflitos nas interações entre comunidades, Estado e instituições, organizações ou outros usuários dos recursos naturais (CASTRO e NIELSEN, 2001).

A alternância nas categorias e divisão dos lagos expõe as fragilidades das relações existentes tanto entre as comunidades e as instituições quanto no interior de cada uma delas. Entre as comunidades é possível observar que não há um acordo bem estabelecido, com regras claras para usos das áreas, levando cada comunidade a agir individualmente nos lagos que tem direito. Com efeito, o engajamento mútuo previsto na ação coletiva para a gestão dos bens e territórios comuns não ocorre. Entre as comunidades e instituições há a falta de diálogo e diferenças nos entendimentos do que é conservação e como estabelecer as áreas de uso e preservação. A contradição ao ideal da "convivência conciliatória" (LEUZINGER, 2016) engajada na conservação da sociobiodiversidade entre as partes ocorre aqui na contramão das iniciativas integrativas e inclusivas de gestão dos ambientes, como expressa o SNUC.

É intrigante pensar então que na medida em que mais ferramentas de gestão participativa são criadas mais os conflitos se tornam aparentes. Nesse sentido, pode-se aferir que a mudança traz com ela o conflito (CASTRO e NIELSEN, 2001), sendo no momento das negociações desses que os interesses dos atores são expostos, especialmente na ordenação dos lagos e repartição de benefícios.

O conhecimento ou entendimento incompleto dos sistemas naturais e sociais sempre vai limitar a efetividade da gestão (ADAMS et al., 2003). Portanto, reconhecer os interesses e a percepção heterogênea das comunidades indígenas e ribeirinhas sobre os recursos naturais, seus direitos coletivos e dos usos do território implica diretamente na gestão das unidades de conservação bem como no manejo dos recursos naturais. Por isso, como propõe a ecologia política (LITTLE 2006), identificar os atores e a natureza desses conflitos é uma importante ferramenta para a proposição de estratégias de condução do manejo dos recursos e na mediação de tais conflitos.

\section{REFERÊNCIAS}

ADAMS W.M, et al., Managing Tragedies: Understanding Conflict over Common Pool Resources, Science 302, 1915-1916, 2003. 
ALENCAR, E. F., Estudo da ocupação humana e mobilidade geográfica de comunidades rurais da Reserva de Desenvolvimento Sustentável Amanã - RDSA. Documento Interno - IDSM, 2006.

BENSUSAN, N, PRATES, A. P. A diversidade cabe na Unidade? Áreas protegidas no Brasil, In BENSUSAN N., PRATES A. N., Brasília, IEB, 2014.

CARDOSO, Thiago M.; ELOY, Ludivine; BARRETTO FILHO, Henyo T; e SILVEIRA Pedro C. B. Apresentação do Dossiê: Antropologia das Áreas Protegidas e da Sustentabilidade. Anuário Antropológico [online], URL: http://journals.openedition.org/aa/4926; DOI: https://doi.org/10.4000/aa.4926

CASTRO P.A, NIELSEN E., Indigenous people and co-management: implications for conflict management, Environmental Science \& Policy 4, 229-239, 2001.

CARNEIRO DA CUNHA, M. Populações tradicionais e a Convenção da Diversidade Biológica. Estudos Avançados 13 (36), 147-163, 1999.

ESCOBAR, A., O lugar da natureza e a natureza do lugar: globalização ou pósdesenvolvimento? In: colonialidade do saber: eurocentrismo e ciências sociais. Perspectivas latino-americanas, Buenos Aires, Consejo Latinoamericano de Ciencias Sociales. Pg. 69-86, 2005.

ESCOBAR, A., Difference and Conflict in the Struggle Over Natural Resources: A political ecology framework, Development 49, 6- 13, 2006.

GELDMANN, J. et al., Changes in Protected Area Management Effectiveness Over Time: A Global Analysis, Biological Conservation 191, 692-699, 2015.

JUNK, W.J. et al., The Flood Pulse Coneept in River-Floodplain Systems. Can. J. Fish. and Aquat. Sei.106, 110-127, 1989.

JUNK, W. J., Flood Pulsing and the Linkages Between Terrestrial, Aquatic, and Wetland Systems, Internationale Vereinigung für theoretische und angewandte Limnologie: Verhandlungen, 29:1, 11-38, 2005.

JUNK, W. J., et al., A classification of Major Natural Habitats of Amazonian WhiteWater River Floodplains (Várzeas), Wetlands Ecol. Manage. 20, 461- 475, 2012.

LEUZINGER, M. D., A gestão compartilhada de áreas protegidas como instrumento de compatibilização de direitos. RIL 53, 253-271, 2016.

LIMA, D. M., As sobreposições em Mamirauá e a Necessidade de um Novo Pacto Institucional. In: RICARDO, F. (Org.) Terras Indígenas e Unidades de Conservação da Natureza: o desafio das sobreposições, São Paulo, Instituto Socioambiental, 2004.

LITLLE, P. E., Os conflitos socioambientais: um campo de estudo e de ação política. In: BURSZTYN, M. (org.). A difícil sustentabilidade: política energética e conflitos ambientais. Rio de Janeiro: Ed. Garamond Ltda, 2001. 
LITTLE, P. E., Ecologia Política como Etnografia: Um Guia Teórico e Metodológico, Horizontes Antropológicos 25, 85-103, 2006

MENDES, Ana Beatriz Vianna et al. Processos decisórios envolvendo populações que residem no Parque Nacional do Jaú (AM). III ENCONTRO DA ANPPAS, 23 a 26 de maio de 2006, Brasília-DF.

NASCIMENTO, A. C. et al., Cenário Demográfico da Reserva de Desenvolvimento Sustentável Amanã, In MARMONTEL M., BENITZT. (ORG), Simpósio sobre Conservação e Manejo Participativo na Amazônia, Livor de Resumos, Tefé, 2019.

NEWIG, J., FRITSCH, O., Environmental Governance: Participatory, Multi-Level - and Effective? Environmental Policy and Governance 19, 197- 214, 2009.

MOURA E. A. et al., Sociodemografia da Reserva de Desenvovimento Sustentável Mamirauá 2001 a 2011, Instituto de desenvolvimento Sustentável Mamirauá, Belém, 2016.

OSTROM, E., Governing the Commons: the Evolution of Institutions for Collective Action, Cambridge, Cambridge University Press, 1990.

OSTROM, E. A behavial approach to the rational choise theory of colletive action. American Political Science Review 92(1), 1-22. 1998.

PERALTA, N., Toda ação de conservação precisa ser aceita pela sociedade: manejo participativo em reserva de desenvolvimento sustentável. Tese (Doutorado em Sociologia), Universidade Federal de Minas Gerais, Belo Horizonte, 2012.

PERALTA, N., Lima, D. M., Guardar é Para Tirar Depois. Disputas territoriais e conceituais em uma unidade de conservação: o caso da RDS Mamirauá, Revista. Hist. 4, 114-138, 2015.

QUEIROZ, H. L. A Pesquisa Científica em Mamirauá: instrumento de consolidação do manejo participativo e da conservação da biodiversidade. In: RICARDO, F. (org). Terras Indígenas e Unidades de Conservação: o desafio das sobreposições, São Paulo, Instituto Socioambiental, 542-548, 2004.

RECHCIŃSKI, M. et al., Protected Area Conflicts: a state-of-the-art review and a proposed integrated conceptual framework for reclaiming the role of geography, Biodiversity and Conservation 28, 2463- 2498, 2019.

RAfFestiN, C., Por Uma Geografia do Poder. São Paulo, Editora Ática, 1993.

REDPATH, S. M. et al., Understanding and Managing Conservation Conflicts, Trends in Ecology \& Evolution, Vol. 28, 100-110, 2013.

REIS, M. B. Arengas \& Picicas: reações populares à Reserva de Desenvolvimento Sustentável no Estado do Amazonas. Belém: Sociedade Civil Mamirauá; Instituto de Desenvolvimento Sustentável Mamirauá., 2005. 
SANTOS, R. B. C., Passar para Índio: Etnografia das emergências indígenas no Médio Solimões. (Relatório Técnico). Processo n 551014/2011-3. IDSM, 2012.

SOUZA, A. M. "Arribando aos mururus". Redeiros, atravessadores, fregueses de patrão e os canoeiros na fronteira do desenvolvimento Sustentável em Tefé. Dissertação (Mestrado em Antropologia) Universidade Federal do Maranhão, São Luís, 2005

SOUZA, M. O., Passar para indígena na Reserva de desenvolvimento Sustentável Amanã, Dissertação (Mestrado em Antropologia), Universidade Federal de Minas Gerais, Belo Horizonte, 2011.

STENGERS, Isabelle. 2005. "Introductory Notes on an Ecology of Practices". Cultural Studies Review 11 (1): 183-196.

\section{NOTAS}

Vinícius Galvão Zanatto

Mestre em Geografia pela Universidade de Brasília (UnB)

Pesquisador no Instituto de Desenvolvimento Sustentável Mamirauá, Grupo de Pesquisa em Territorialidades e Governança Socioambiental na Amazônia.

vinicius.zanatto@mamiraua.org.br

Ohttps://orcid.org/0000-0002-1825-0097

\section{Patrícia Carvalho Rosa}

Doutora em Antropologia pela Universidade Estadual de Campinas (UNICAMP)

Pesquisadora titular no Instituto de Desenvolvimento Sustentável Mamirauá, Grupo de Pesquisa em Territorialidades e Governança Socioambiental na Amazônia

patricia.rosa@mamiraua.org.br

Dhttps://orcid.org/0000-0001-7570-3702

Endereço de correspondência do principal autor

Estrada do Bexiga, 2.584 - Fonte Boa, C.P 38 - 69553-225 - Tefé - Amazonas - Brasil

\section{AGRADECIMENTOS}

Agradecemos o apoio e conhecimentos compartilhados com o Programa de Manejo de Recursos Pesqueiros do IDSM e a cooperação da Coordenação Regional da Funai na realização dessa fase inicial da pesquisa.

\section{CONTRIBUIÇÃO DE AUTORIA}

Concepção e elaboração do manuscrito: V.G. Zanatto, P.C. Rosa

Coleta de dados: V.G. Zanatto, P.C. Rosa

Análise de dados: V.G. Zanatto, P.C. Rosa

Discussão dos resultados: V.G. Zanatto, P.C. Rosa

CONJUNTO DE DADOS DE PESQUISA

Todo o conjunto de dados que dá suporte aos resultados deste estudo foi publicado no próprio artigo

\section{FINANCIAMENTO}

Financiamento pelo CNPq por meio de bolsa PCI via MCTIC. Projeto no 444292/2018-7

CONSENTIMENTO DE USO DE IMAGEM

NÃO SE APLICA.

APROVAÇÃO DE COMITÊ DE ÉTICA EM PESQUISA NÃO SE APLICA 


\section{CONFLITO DE INTERESSES \\ NÃO SE APLICA}

LICENÇA DE USO - uso exclusivo da revista

Os autores cedem à Revista Internacional Interdisciplinar INTERthesis os direitos exclusivos de primeira publicação, com o trabalho simultaneamente licenciado sob a Licença Creative Commons Attribution (CC BY) 4.0 International. Estra licença permite que terceiros remixem, adaptem e criem a partir do trabalho publicado, atribuindo o devido crédito de autoria e publicação inicial neste periódico. Os autores têm autorização para assumir contratos adicionais separadamente, para distribuição não exclusiva da versão do trabalho publicada neste periódico (ex.: publicar em repositório institucional, em site pessoal, publicar uma tradução, ou como capítulo de livro), com reconhecimento de autoria e publicação inicial neste periódico.

PUBLISHER - uso exclusivo da revista

Universidade Federal de Santa Catarina. Programa de Pós-graduação Interdisciplinar em Ciências Humanas. Publicação no Portal de Periódicos UFSC. As ideias expressadas neste artigo são de responsabilidade de seus autores, não representando, necessariamente, a opinião dos editores ou da universidade.

\section{EDITORES}

Javier Ignacio Vernal, Silmara Cimbalista e Selvino José Assmann (In Memoriam).

EDITOR ASSISTENTE - Eixo temático: “Amazônia: povos, conflitos e preservação” Luiz Barp

HISTÓRICO - uso exclusivo da revista

Recebido em: 21-11-2019 - Aprovado em: 30-06-2020 - Publicado em: 31-07-2020 